\title{
Future of Vinyl Banners: Chemical Composition, Toxicity, Environmental Impact and Degradation
}

\author{
Saroj Yadav, Swati Baliyan, Guru Prasad V and Sibi G* \\ Department of Biotechnology, Indian Academy Degree College- Autonomous, India
}

Submission: November 17, 2018; Published: December 03, 2018

*Corresponding author: Sibi G, Head of the Department, Department of Biotechnology, Indian Academy Degree College- Autonomous, Bangalore, India

\section{Abstract}

Poly vinyl chloride (PVC) is a thermoplastic of about 800-1500 monomer units long. Due to its low cost, desirable properties and versatility, PVC can be processed into a wide range of short-life products. As a result of increasing consumption of PVC-made products, the quantity of used PVC items entering the waste stream is gradually increased. One application of PVC is as either a thin or thick coating for flexible polyester advertising banners. PVC-coated banners are particularly challenging for recycling, as the PVC is bonded to another polymer, usually polyester. The whole life cycle of polyvinyl chloride banner industry releases a lot of solid wastes, air wastes, water wastes and other environmental toxins. Cross-linking, thermooxidative degradation of polymer and plasticizers, polymer dehydrochlorination, and diffusional desorption of a plasticizer occurs in aged PVC materials. Biodegradation of PVC leads to reduction of polymer molecular weight due to the shortening of the polymer chains and elimination of their fragments. Microorganisms are capable of degrading inorganic and organic materials, and interest has been aroused to study microbes for their ability to degrade synthetic polymers. The replacement of slowly degradable materials with biodegradable materials is other ecological alternative addressing the problem of waste surging in the environment caused by vinyl banners.

Keywords: Poly vinyl chloride; Biodegradation; Flex banner; Polymers

\section{Introduction}

Polymers are the molecules whose structure contains multiple repeating units, which results into a compound of high relative molecular mass and associated properties. Features of synthetic polymers such as chemical, physical and biological inertness, durability, low density and low cost has made their production efficient and easy, resulting in their accumulation in the environment [1,2]. The most widely used polymers contributing to plastic waste are polyethylene, polyvinyl chloride, polystyrene and polypropylene [3]. Polymer degradation and recycling is intended to prevent the environmental pollution caused by their production as they are often disposed in landfills or water. Sustainable development is a worldwide strategy considering ecological, economic, and social issues. The printing industry creates traditionally short-term products, such as newspapers, magazines, and packaging. The printing techniques like flexographic, offset, and digital printing, for a specific printed product gives some general information about the potential impact of printed products. Thus, the technological background of the production of printed products has an essential influence on the main contributors, like energy, materials, and hazardous waste [4].

\section{Aging of polymers}

Aging is a process causing structural changes in the material and in its chemical composition as well as reduction of its molecular weight, leading to changes in the functional properties of a polymer. As a result of aging processes, polymers undergo thermal, oxidative, chemical, radiation, mechanical, or biological degradations.

\section{Spontaneous and artificial aging}

Spontaneous (natural) progress is very slow, but irreversible and unstoppable. It can be caused by external (environmental) and internal factors. The first one includes light, ionizing radiation, electric, electromagnetic and ultrasonic fields, heat, physically or chemically active media and microorganisms. Internal factors include, for example, composition of the material and its structure or way of production, as well as internal stress in the material, presence of a catalyst, cracks, reactive groups, or weak bonds. Artificial aging is intended to produce time dependent changes in much shorter time than during the natural process. Properties of materials depend on factors such as temperature, humidity, and light, especially in the UV region, as well as the action of gases.

\section{Degradation process}

Degradation is a change in the structure of the polymeric material as a result of shortening its chain; that is, the distribution of macromolecules into fragments of lower molecular weight. The degradation may be either chemical or physical in nature. Typically, these changes are irreversible as a result of chemical reactions, such as cross-linking, thermal 
oxidation, chain breaking, or destruction. Other processes include depolymerization, adsorption, absorption, desorption, or transformation of a group of atoms. Main factors causing degradation are radiation, oxidation, and temperature.

\section{Abiotic and biotic degradation}

Abiotic processes take place under the influence of mechanical forces, electromagnetic radiation, heat, or active compounds. In biotic process, the degradation occurs as a result of the activity of biological agents, in particular, enzymes produced by fungi and bacteria.

\section{Degradation mechanisms of polymer materials}

Radiation: Photodegradation is a process that changes the basic structure of a polymer by cross-linking, chain scission, and oxidative processes. Photooxidation is a process that occurs mainly on the surface of the material. Thickness of polymer films or plates is an important factor in photodegradation process [5]. High-energy radiation also leads to radiation degradation of polymers. It is caused by interaction of photons of $\mathrm{x}$-rays and $\gamma$-rays in the polymer.

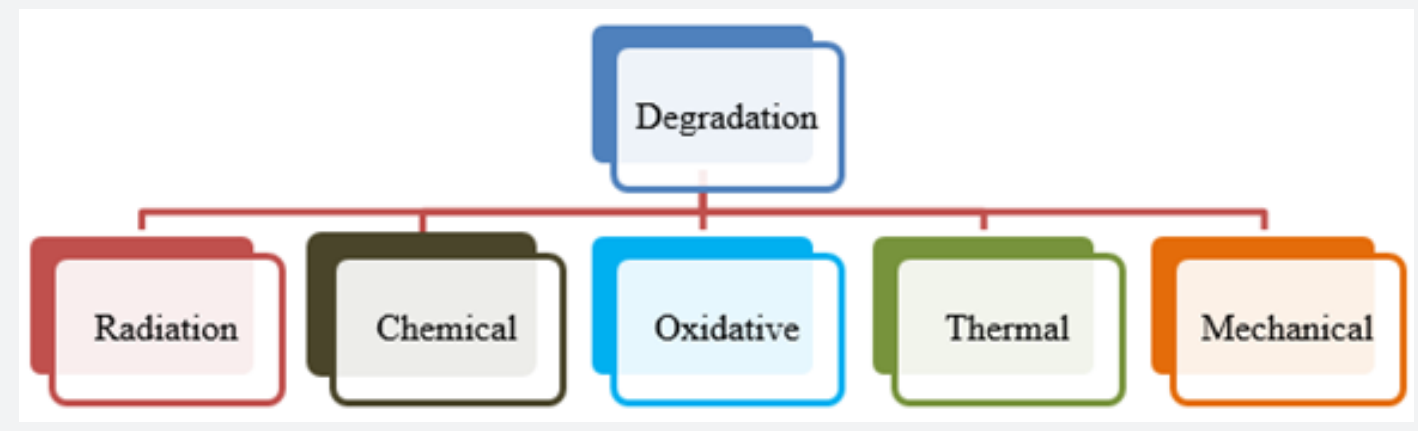

Figure 1: Degradation of Polymer Materials.

Chemical degradation: Chemical degradation processes are a result of direct action of various chemical compounds on a polymeric material. Chemical agents may include: acids, alkalis, solvents, or reactive gases (Figure 1).

Oxidative degradation: Oxidative degradation involves the disintegration of macromolecules by the action of oxygen on the substrate. Free radicals are formed and react with each other or remove hydrogen from polymer chains [6]. Oxidative degradation not only leads to chemical structure changes in polymers, but also to scratches and fine cracks on the material surface. This leads to a reduction in polymer molecular weight due to the breakage of molecular chain or its increase by crosslinking or chain branching.

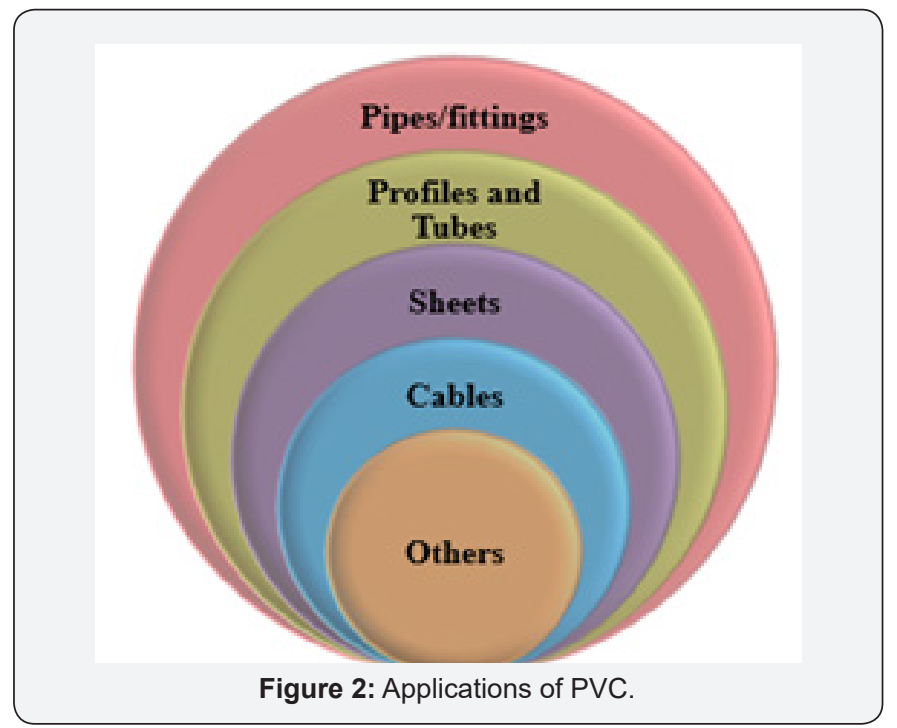

Thermal degradation: Thermal degradation occurs when the polymer changes its properties under the influence of increased temperature. There are three types of thermal degradation. The first is the disruption of the polymer backbone and complete degradation. The latter involves only breaking of bonds in the side chain leading to creation of volatile products. The last includes cross linking processes [7].

Mechanical degradation: Mechanical degradation of the polymers occurs as a result of the presence of stresses in the polymer. Stresses in the form of micronotch concentrate in the weakened spots initiating the destruction of the polymer.

Polyvinylchloride (PVC): Polyvinylchloride (PVC) is a thermoplastic and the third largest production polymer in the world [8]. PVC can be rigid or flexible, clear or opaque. When PVC is compounded with a plasticizer, it is flexible. Examples of flexible PVC products are upholstery and clothing; wall covering, blood and IV bags, and tubing; wrap film, shower curtains, wire insulation and coatings on metal sheet. Rigid PVC contains rigid-specific additives such as impact modifiers. Rigid PVC applications include pipe, siding, windows, fence and many custom profiles for furniture, automotive, and industrial applications. In general, PVC molecules are about 800-1500 monomer units long. Because of the particular properties inherent in the PVC such as its low cost and high performance, combined with the wide range of products that can be obtained from different processing conditions and techniques, PVC has become a universal polymer [9-12]. PVC is one of the world's top five raw materials for general synthetic resin with a yield ranking second only behind polyethylene in the world of 
plastics. Due to its low cost, desirable properties and versatility, PVC can be processed into a wide range of short-life products such as packaging for food, beverages and cleaning products, medical devices and is widely used as a weatherproof coating for banners, tarpaulins and grain covers. One application of PVC is as either a thin or thick coating for flexible polyester advertising banners, to create durable, light weight products with good tensile strength that also provide the water, wind and wear and tear resistance required for extended outdoor use. As a result of increasing consumption of PVC-made products, the quantity of used PVC items entering the waste stream is gradually increased. The disposal of PVC waste has gained increasing importance in the public discussion in recent years (Figure 2).

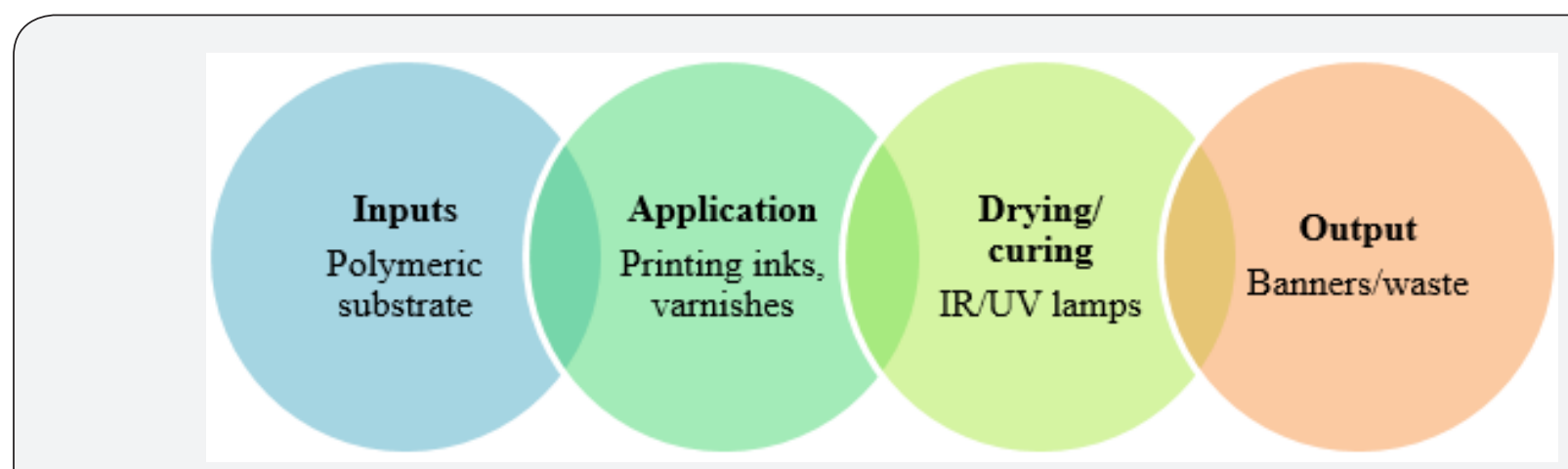

Figure 3: Banner Printing Process.

PVC-coated banners are particularly challenging for recycling, as the PVC is bonded to another polymer, usually polyester. The whole life cycle of polyvinyl chloride banner industry releases a lot of solid wastes, air wastes, water wastes and other environmental toxins that are hurting the environment and the new generation. The energy consumption of a solvent-based coating, which is usually dried by IR light, is much higher than that of the pure UV coating. UV curing with mercury vapor lamps potentially produces ozone emissions. Isopropyl alcohol and the aromatic hydrocarbons "toluene" are commonly used solvents in printing technology. These chemicals emitting into the air during the printing process have potential for photochemical ozone formation. Besides emissions in the printing production, the potential for emissions afterward could be relevant. The toluene retained in the printed products has human health risk potential $[13,14]$ (Figure 3).

PVC production and its impact: The first step in the PVC production process is the generation of elemental chlorine. This gas is created in chlor-alkali facilities by running an electrical current through salty brine in the presence of a catalyst, mercury. When elemental mercury from chlorine manufacturing plants is released to the atmosphere as a vapor, it can be carried long distances before returning back to earth. Once it does, methylating bacteria quickly convert the metal into an organic form, methylmercury, which is a powerful brain poison as well as a bioaccumulating, persistent pollutant. From here, it is quickly siphoned up the food chain, reaching its highest levels in fish and seafood. Once chlorine is generated and combined with carbon to form ethylene dichloride, the next major step in the PVC manufacturing process is the synthesis of vinyl chloride monomer. The ability of vinyl chloride to cause angiosarcoma of the liver is well known. A study found that among PVC workers significantly increased mortality from all causes of death, all tumors, lung cancer, lymphomas, leukemias, and liver cirrhosis [15]. PVC manufacture involves the polymerization of vinyl chloride monomer and this process creates a fine powder, which is handled by workers known as PVC baggers. Studies have documented increased rates of lung cancer and other pulmonary diseases within this group of workers $[16,17]$.

In addition to the volatilization of organic chemicals in PVC products, threats to human health associated with the use of polyvinyl chloride building materials can originate from degradation of the vinyl material itself. There is also growing concern about the endocrine-disrupting potential of the phthalate plasticizers used to make PVC pliable. Burning of polyvinylchloride (PVC) plastics produces persistent organic pollutants (POPs) known as furans and dioxins [18] (Figure 4).

Poly vinyl chloride degradation: Poly vinyl chloride (PVC) products are often exposed to outdoor conditions and thus vulnerable to the environmental factors. The following processes can occur in aged PVC materials: cross-linking, thermooxidative degradation of polymer and plasticizers, polymer dehydrochlorination, and diffusional desorption of a plasticizer [19]. Generally, weathering causes the degradation of PVC polymers. As a result of breakage of chemical bonds, the material loses its properties. The mechanism of free radicals occurs, and mechanisms of oxidation, yellowing, bleaching, and surface erosion can also be observed [20]. Yellowness was noticed in PVC films prior to a serious loss in strength. PVC undergoes rapid autocatalytic dehydrochlorination upon exposure to heat and light during its molding and use [21,22]. PVC decomposes at a temperature lower than its processing temperature [23]. Degradation also causes a drastic change in the mechanical properties of the polymer, which is accompanied by a decrease or increase in its average molecular weight. 


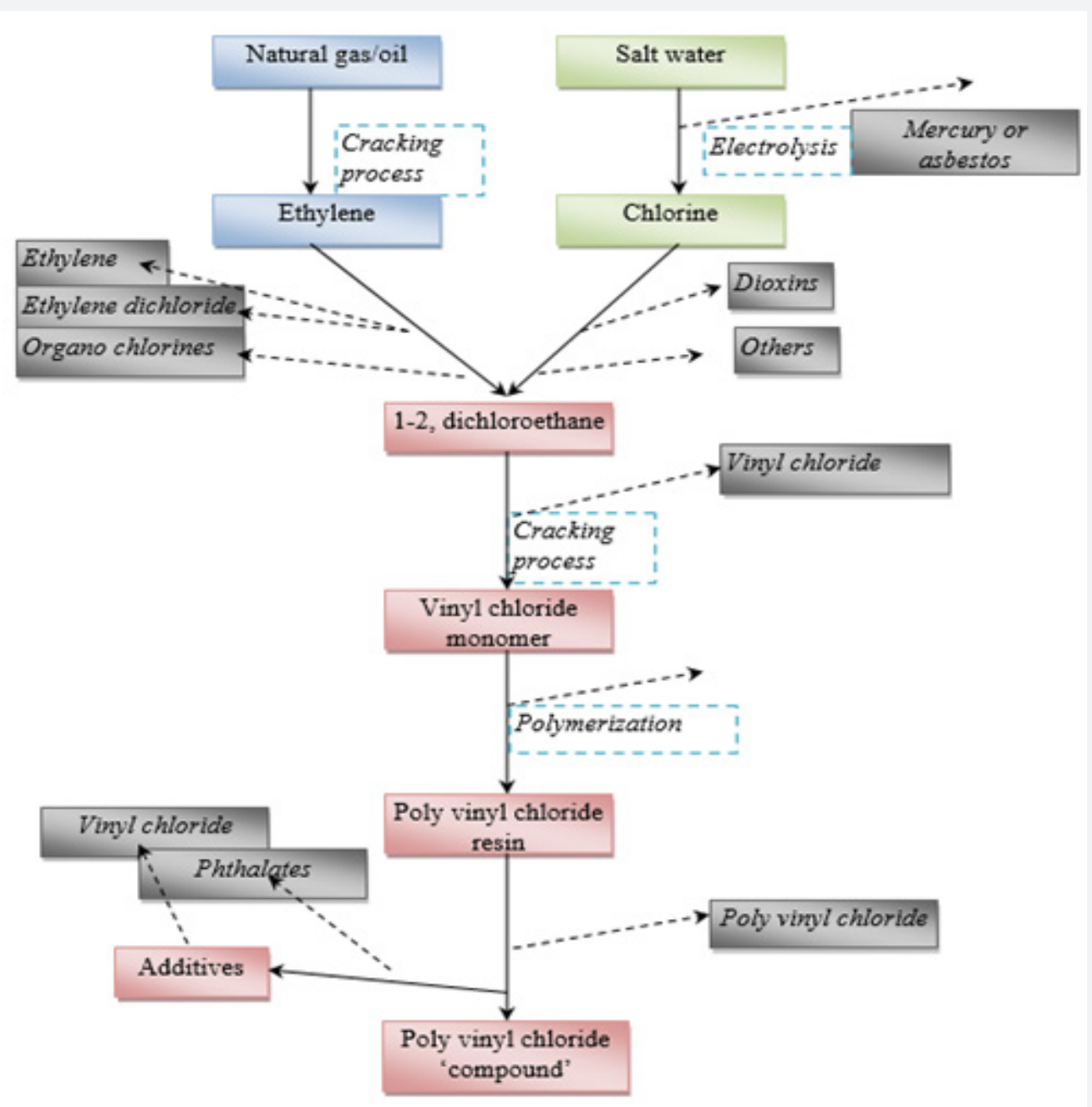

Figure 4: Release of chemicals during PVC production.

Biological degradation of poly vinyl chloride (PVC): PVC is a strong plastic that resists abrasion and chemicals and has low moisture absorption. Many studies have focused on the thermal and photodegradation of PVC, but few reports are available on PVC biodegradation [24]. Biodegradation leads to reduction of polymer molecular weight due to the shortening of the polymer chains and elimination of their fragments. Biodegradation processes are divided into aerobic and anaerobic. Former process takes place with the participation of oxygen, and the main products of decomposition are $\mathrm{CO} 2$, water, and biomass. The latter process occurs under anaerobic conditions, thus producing methane instead of $\mathrm{CO} 2$. Biodegradation of polyvinylchloride (PVC) by white rot fungi was studied by [25]. Degradation of PVC by Pseudomonas putida was reported by [26]. The biodegradability of PVC by Micrococcus species with PVC as a sole carbon source was determined by [27]. The results showed that $0.36 \%$ release of chloride and $8.87 \%$ mineralization measured in terms of carbon dioxide evolution respectively over a period of 70 days in PVC containing media. Members of the genera Pseudomonas and Brevibacterium were reported to deteriorate PVC in laboratory conditions. PVC pipes exposed to water microorganisms have shown bacterial attachment and formation of extracellular material on their internal surfaces [28].

The total degradation of a polymer chain in the presence of aerobic organisms causes oxidation in the chain, producing $\mathrm{CO} 2$ and $\mathrm{H}_{2} \mathrm{O}$ (mineralization) [29]. Growth of Aspergillus fischeri and Paecilomyces species on plasticized polyvinyl film in liquid medium was reported by [30]. Degradation of PVC was higher than poly vinyl alcohol, polycapro lactone in the soil as reported by de [31]. Biodegradation of pPVC by fungal species has been reported earlier [32-34]. studied the fungal colonization of soil-buried plasticized polyvinyl chloride and found that Penicillium janthinellum as a principal colonizer. [35] reported that biodegradation of PVC by Trichocladium sp. and Chaetomium sp. in soil. The results of weight loss for PVC blend with cellulose and cell samples exposed to Trichocladium sp. was two-fold higher than that of PVC blend with cellulose alone. The biodegradation of starch blended polyvinyl chloride films by Phanerochaete chrysosporium through release of higher $\mathrm{CO} 2$ $(7.85 \mathrm{~g} / \mathrm{l})$ compared to control $(2.32 \mathrm{~g} / \mathrm{l})$ was recorded by [36- 
39]. Aureobasidium pullulans was reported to grow with the intact plasticized PVC formulation as the sole source of carbon, degrade the plasticizer, produce extracellular esterase, and cause weight loss of the substratum during growth in vitro [33].

\section{Conclusion}

Knowledge of degradation processes is important for technical, engineering, and economical reasons. Microorganisms are capable of degrading inorganic and organic materials, and interest has been aroused to study microbes for their ability to degrade synthetic polymers. The replacement of slowly degradable materials with biodegradable materials is other ecological alternative addressing the problem of waste surging in the environment caused by vinyl banners.

\section{References}

1. Song JH, Murphy RJ, Narayan R, Davies GBH (2009) Biodegradable and compostable alternatives to conventional plastics. Philos Trans R Soc Biol 364: 2127-2139.

2. Dey U, Mondal NK, Das K, Dutta S (2012) An approach to polymer degradation through microbes. J Pharm 2(3): 385-388.

3. Puri N, Kumar B, Tyagi H (2013) Utilization of recycled wastes as ingredients in concrete mix. Int J Innov Technol Explor Eng 2: 74-78.

4. Enroth M, Johansson M (2006) Environmental data on gravure and offset printing. Acta Graphica 18(1-4): 1-10.

5. RabekJF (1996) Photodegradation of polymers. Physical characteristics and applications. Berlin, Springer.

6. Iannuzzi G, Mattsson B, Rigdahl M (2013) Color changes due to thermal ageing and artificial weathering of pigmented and textured ABS. Polymer Engineering and Science 53(8): 1687-1695.

7. Pielichowski K, Njuguna J (2005) Thermal degradation of polymeric materials. Rapra Technology Limited, Shawbury, England.

8. Stichnothe H, Azapagic A (2013) Life cycle assessment of recycling PVC window frames. Resour Conserv Recycl 71: 40-47.

9. Garcia D, Balart R, Crespo JE, Lopez J (2006) Mechanical properties of recycled PVC blends with styrenic polymers. J Appl Polym Sci 101(4): 2464-2471.

10. Yarahmadi N, Jakubowicz I, Martinsson L (2003) PVC floorings as postconsumer products for mechanical recycling and energy recovery. Polym Degrad Stabil 79(3): 439-448.

11. Braun D (2001) PVC origin, growth, and future. J Vinyl Addit Technol $7(4): 168-176$.

12. La Mantia FP (1996) Recycling of PVC and mixed plastic waste. ChemTec Publishing, Toronto, Canada.

13. Walser T, Juraske R, Demou E, Hellweg S (2013) Indoor exposure to toluene from printed matter matters: complementary views from life cycle assessment and risk assessment. Environmental Science \& Technology 48(1): 689-697.

14. Gustafsson LM, Borjesson P (2007) Life cycle assessment in green chemistry. International Journal of Life Cycle Assessment 12: 151-159.

15. Gennaro V, Ceppi M, Montanaro F (2003) Re analysis of mortality in a petrochemical plant producing vinyl chloride and polyvinyl chloride. Epidemiol Prev 27: 221-225.

16. Xu H, Verbeken E, Vanhooren HM, Nemery B, Hoet PH (2004) Pulmonary toxicity of polyvinyl chloride particles after a single intratracheal instillation in rates Time course and comparison with silica. Toxicology and Applied Pharmacology 194(2): 111-121.
17. Mastrangelo G (2003) Lung cancer risk in workers exposed to poly (vinyl chloride) dust: A nested case-referent study. Occupational and Environmental Medicine 60(6): 423-428.

18. Jayasekara R, Harding I, Bowater I, Lornergan G (2005) Biodegradability of selected range of polymers and polymer blends and standard methods for assessment of biodegradation. J Polym Environ 13(3): 231-251.

19.Zaikov GE, Gumargalieva KZ, Pokholok TV, Moiseev YV, Zaikov VG (2000) Kinetic aspects of aging of poly (vinyl chloride)-based polymer materials. Polymer-Plastics Technology and Engineering 39(3): 567650.

20. Jakubowicz I (2001) Effects of artificial and natural ageing on impactmodified poly (vinyl chloride) (PVC) Polymer Testing 20(5): 545-551.

21. Yousif E, Aliwi M, Ameer A, Ukal J (2009) Improved photostability of PVC films in the presence of 2-thioacetic acid-5-phenyl-1,3,4oxadiazole complexes. Turk J Chem 33(3): 339-410.

22. Sabaa ME, Oraby A, Abdel Naby, R Mohamed (2006) N phenyl 3 substituted 5 pyrazolone derivatives as organic stabilizers for rigid poly (vinyl chloride) against photodegradation J Appl Polym Sc 101(3): 1543-1555.

23. Arkis A, Balkose D (2004) Thermal stabilization of poly (vinyl chloride) by organotin compounds. Polym Degrad Stab 88(1): 46-51.

24. Shah AA, Hasan F, Hameed A, Ahmed S (2008) Biological degradation of plastics: A comprehensive review. Biotechnology Advances 26(3): 246265.

25. Kirbas Z, Keskin N, Guner A (1999) Biodegradation of polyvinylchloride (PVC) by white rot fungi. Bull Environ Contam Toxicol 63(3): 335-342.

26. Danko AS, Luo M, Bagwell CE, Brigmon RL, Freedman DL (2004) Involvement of linear plasmids in aerobic biodegradation of vinyl chloride Appl Environ Microbiol 70(10): 6092-6097.

27. Patil R, Bagde US (2012) Isolation of polyvinyl chloride degrading bacterial strains from environmental samples using enrichment culture technique. African Journal of Biotechnology 11: 7947-7956.

28. Vess RW, Anderson RL, Carr JH, Bond WW, Favero MS (1993) The colonization of solid PVC surfaces and the acquisition of resistance to germicides by water micro-organisms. J Appl Microbiol 74(2): 215221.

29. Martins-Franchetti SM, Marconato JC (2006) Biodegradable polymers A solution to reduce the amount of plastic waste. Chem Nova 29:811 816.

30. Roberts WT, Davidson PM (1986) Growth characteristics of selected fungi on polyvinyl chloride film. Appl. Environ Microbiol 51(4): 673676.

31. de Campos A, Marconato JC, Franchetti SMM (2011) Biodegradation of blend films PVA/PVC, PVA/PCL in soil and soil with landfill leachate. Braz Arch Biol Technol 54: 1367-1378.

32. Upsher FJ, Roseblade RJ (1984) Assessment by tropical exposure of some fungicides in plasticized PVC. Int Biodeterior 20: 243-252.

33. Webb JS, Nixon M, Eastwood IM, Greenhalgh M, Robson GD, et al. (2000) Fungal colonization and biodeterioration of plasticized polyvinyl chloride. Appl Environ Microbiol 66: 3194-3200.

34. Sabev HA, Handley PS, Robson GD (2006) Fungal colonization of soil-buried plasticized polyvinyl chloride (pPVC) and the impact of incorporated biocides. Microbiol 152(6): 1731-1739.

35. Kaczmarek H, Bajer K (2007) Biodegradation of plasticized poly (vinyl chloride) containing cellulose. Polym Sci 45(8):903-919.

36. Ali MI, Perveen Q, Ahmad B, Javed I, Hussnain R, et al. (2009) Studies on biodegradation of cellulose blended polyvinyl chloride films. Int J Agric Biol 11(5): 577-580. 
37. Belhaneche-Bensemra N (2002) Influence of atmospheric pollutants on the natural and artificial aging of rigid poly (vinyl chloride) Journal of Vinyl and Additive Technology 8(1): 45-54.

38. Booth GH, Cooper AW (1968) Bacterial Degradation of Plasticized PVC J Appl Environ Microbiol 31(3): 305-310.

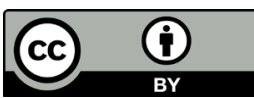

his work is licensed under Creative Commons Attribution 4.0 License

DOI: 10.19080/IJESNR.2018.15.555916
39. Kaczmarek H, Bajer K (2006) Study on biodegradation of polymeric materials. Part I Basic definitions and methods of evaluation of biodegradation of polymer materials. Polimery 51: 716-721.

Your next submission with Juniper Publishers will reach you the below assets

- Quality Editorial service

- Swift Peer Review

- Reprints availability

- E-prints Service

- Manuscript Podcast for convenient understanding

- Global attainment for your research

- Manuscript accessibility in different formats (Pdf, E-pub, Full Text, Audio)

- Unceasing customer service

Track the below URL for one-step submission https://juniperpublishers.com/online-submission.php 